\title{
Pengaruh Senam Prolanis terhadap Penurunan Tekanan Darah pada Penderita Hipertensi di Wilayah Pesisir Puskesmas Soropia
}

\section{The Effect of Prolanis Gymnastics on Decreasing Blood Pressure in Hypertension Patients in the Coastal Area of the Soropia Public Health Center}

\author{
Inriani, Inriani; Narmawan, Narmawan; Abadi, Ellyani
}

\section{Inriani Inriani}

Program Studi Sarjana Keperawatan, STIKes Karya

Kesehatan , Indonesia

Narmawan Narmawan

narmawanfebson@gmail.com

Program Studi Sarjana Ilmu Keperawatan, STIKes

Karya Kesehatan, Indonesia

Ellyani Abadi

Program Studi Sarjana Gizi, STIKes Karya

Kesehatan, Indonesia

Health Information: Jurnal Penelitian

Poltekkes Kemenkes Kendari, Indonesia

ISSN: 2085-0840

ISSN-e: 2622-5905

Periodicity: Bianual

vol. 13 , no. 1,2021

jurnaldanhakcipta@poltekkes-kdi.ac.id

Received: 16 November 2020

Accepted: 20 May 2021

URL: http://portal.amelica.org/ameli/journal/504/5042198001/

DOI: https://doi.org/10.36990/hijp.v13i1.232

Corresponding author: narmawanfebson@gmail.com

Authors retain copyright and grant the journal right of first

publication with the work simultaneously licensed under a Creative Commons Attribution-ShareAlike 4.0 International License that allows others to share the work with an acknowledgment of the works authorship and initial publication in this journal and able to enter into separate, additional contractual arrangements for the nonexclusive distribution of the journals published version of the work (e.g., post it to an institutional repository or publish it in a book).

This work is licensed under Creative Commons AttributionShareAlike 4.0 International.
Ringkasan: Hipertensi atau tekanan darah tinggi adalah suatu peningkatan abnormal tekanan darah dalam pembuluh darah arteri. Prolanis merupakan program pemerintah yang ditujukan kepada penderita penyakit kronis seperti hipertensi agar mampu mengontrol tekanan darahnya. Penelitian ini bertujuan untuk mengetahui pengaruh senam prolanis terhadap penurunan tekanan darah pada penderita hipertensi di Wilayah Pesisir Puskesmas Soropia. Penelitian menggunakan metode Pre experimental dengan one group pre-test post-test. Populasi dalam penelitian ini adalah seluruh pasien hipertensi yang mengikuti senam Prolanis berjumlah 30 orang dengan jumlah sampel 30 orang yang dimabil secara Total Sampling. Variabel penelitian bebas penelitian adalah senam prolanis dan variabel terikat adalah tekanan darah. Analisis statistik menggunakan uji wilcoxon. Hasil penelitian menunjukkan bahwa pretest diperoleh ratarata tekanan darah sistole adalah $160.10 \mathrm{mmHg}$ dan diastole adalah $94.50 \mathrm{mmHg}$ dan posttest rata-ratatekanan darah sistole adalah $151.47 \mathrm{mmHg}$ dan diastole adalah $87.07 \mathrm{mmHg}$. Analisis uji wilcoxon menunjukkan bahwa untuk tekanan darah sistol diperoleh nilai p $0.001<0.05$ dan tekanan darah diastole diperoleh nilai $\mathrm{p}$ value $0.001<0.05$. Simpulan bahwa terdapat pengaruh senam Prolanis terhadap penurunan tekanan darah pada penderita hipertensi di wilayah pesisir Puskesmas Soropia.

Kata kunci: Hipertensi, Senam prolanis, Tekanan darah.

Abstract: Hypertension or high blood pressure is an abnormal increase in blood pressure in the arteries. Prolanis is a government program aimed at sufferers of chronic diseases such as hypertension in order to be able to control their blood pressure. This study aims to determine the effect of prolanic exercise on blood pressure reduction in hypertensive patients in the Coastal Area of ??Soropia Public Health Center. This research used pre experimental method with one group pre-test posttest. The population in this study were all hypertensive patients who participated in Prolanis exercise totaling 30 people with a total sample of 30 people who were stabilized by total sampling. The independent research variable was prolanis exercise and the dependent variable was blood pressure. Statistical analysis using 


\begin{abstract}
the Wilcoxon test. The results showed that in the pretest, the mean systolic blood pressure was $160.10 \mathrm{mmHg}$ and diastole was $94.50 \mathrm{mmHg}$ and the post-test mean systolic blood pressure was $151.47 \mathrm{mmHg}$ and diastolic was $87.07 \mathrm{mmHg}$. Wilcoxon test analysis showed that for systolic blood pressure, the $\mathrm{p}$ value was $0.001<0.05$ and for diastolic blood pressure, the p value was 0.001 $<0.05$. The conclusion is that there is an effect of Prolanis exercise on blood pressure reduction in hypertensive patients in the coastal areas of the Soropia Public Health Center.
\end{abstract}

Keywords: Blood pressure, Hypertension, Prolanis gymnastic.

\title{
PENDAHULUAN
}

Hipertensi merupakan kondisi dimana terjadi peningkatan tekanan darah, di pembuluh darah arteri yang berperan sebagai transportasi zat-zat nutrisi dalam bentuk darah yang dimulai dari jantung yang selanjutnya diedarkan keseluruh jaringan tubuh (Sartik et al., 2017). Hipertensi tergolong salah satu dari sepuluh penyebab utama kematian masyarakat diseluruh dunia khususnya yang tinggal di wilayah pesisir dan muara dan muara (Yodang \& Nuridah, 2019).

World Health Organization (WHO) melaporkan kasus hipertensi meningkat dari 594 juta menjadi 1,13 miliar orang pada tahun 2015 di seluruh dunia (WHO, 2019). Berdasarkan hasil Riset Kesehatan Dasar (Riskesdas) tahun 2018 sebanyak 34,1\% masyarakat usia lebih dari 18 tahun mengalami hipertensi (Kementerian Kesehatan RI, 2018). Sedangkan di Provinsi Sulawesi Tenggara, kejadian hipertensi dalam kurun waktu lima tahun terakhir (2015-2019) adalah sebesar 22.312, 29.749, 31.817, 36.243 dan 37.887 (Dinkes Sultra, 2018).

Pemerintah telah berupaya menanggulangi angka kesakitan akibatan hipertensi melalui berbagai program, diantaranya membentuk Badan Penyelenggara Jaminan Sosial Kesehatan Masyarakat (BPJS) dan Program Pengelolaan Penyakit Kronis (Prolanis). Kedua program ini saling terintegrasi dengan kerjasama layanan kesehatan dari BPJS khusus pada masyarakat yang menderita penyakit kronis dengan tujuan agar tercapai kualitas hidup yang optimal (BPJS, 2015). Kualitas hidup penderita hipertensi mempunyai hubungan yang signifikan dengan pelaksanaan program Prolanis (Sari, 2017). Hal ini karena senam Prolanis yang merupakan salah satu bagian dari implementasi program tersebut memiliki pengaruh terhadap tekanan darah penderita hipertensi (Mulfianda \& Tahlil, 2018).

Senam prolanis memacu jantung untuk berkontraksi secara maksimal, dimana energi yang dihasilkan dari aktivitas olahraga ini dapat memaksimalkan kebutuhan sel-sel pada jaringan tubuh sehingga dapat meningkatkan aktivitas pernafasan, termasuk otot (Marasinta, 2016). Jenis senam lain yang mempunyai efek terhadap tekanan darah adalah senam bugar, dimana saat berolahraga denyut jantung dan pernafasan meningkat, otot memerlukan oksigen yang lebih banyak maka terjadi vasodilatasi pembuluh darah sehingga banyak aliran darah yang terhalang ke otot yang aktif termasuk aliran darah ke jaringan tubuh yang tidak aktif, kontraksi otot polos meningkat dan aliran ke perifer menurun secara tiba-tiba sehingga tekanan darah (TD) sistol dan diastol rendah (Carey et al., 2018). 
Prolanis merupakan program pemerintah yang ditujukan bagi penderita penyakit kronis seperti hipertensi agar mampu mengontrol tekanan darahnya. Hasil studi oleh Zuraidah et al., (2012) bahwa dari 160 orang responden yang mengikuti senam prolanis, 51,2\% menderita hipertensi (Zuraidah et al., 2012). Studi literatur oleh Yodang \& Nuridah (2019) bahwa prevalensi hipertensi khusus di daerah pesisir berkisar antara 6,45\% hingga 51,1\% (Yodang \& Nurindah, 2019).

Wilayah Soropia termasuk dalam kategori daerah pesisir dengan kejadian hipertensi yang cukup tinggi pada setiap tahunnya. Jumlah penderita hipertensi se Kabupaten Konawe pada tahun 2016 tercatat sebanyak 10.559 penderita, tahun 2017 sebanyak 9.933 penderita, tahun 2018 sebanyak 13.140 penderita dan tahun 2019 sebanyak 11.773 penderita (Dinas Kesehatan Konawe, 2018). Data dari Puskesmas Soropia, diketahui bahwa penyakit hipertensi termasuk urutan ke-2 dari sepuluh besar penyakit tahun 2018. Penderita hipertensi di tahun 2018 sebanyak 327 penderita, tahun 2019 sebanyak 311 penderita, dan pada tahun 2020 periode bulan Januari sampai Mei sebanyak 176 penderita dengan rata-rata kunjungan pasien 30 orang perbulannya (Puskesmas Soropia, 2019; Puskesmas Soropia 2020). Sementara partisipasi dalam kegiatan Prolanis masih rendah, untuk tahun 2020 hingga bulan Mei hanya tercatat 17,1\% yang aktif ikut dalam kegiatan tersebut (Puskesmas Soropia, 2020). Berdasarkan studi pendahuluan pada 8 (delapan) orang penderita hipertensi, meraka tidak ikut kegiatan Prolanis sebab menurut mereka senam sama halnya dengan pekerjaan sehari-hari.

\section{METODE}

\section{Jenis Penelitian}

Kajian ini adalah penelitian kuantitatif dan desain praeskperimental pada satu grup pra-pascates. Sebagai variabel independen adalah senam prolanis dan variabel dependennya tekanan darah.

\section{Lokasi, Waktu, Populasi dan Sampel}

Penelitian dilaksanakan di Puskesmas Soropia Kabupaten Konawe mulai tanggal 8-22 September 2020 dengan populasi adalah semua penderita hipertensi yang aktif melakukan senam Prolanis dan dengan metode total sampling didapatkan sebanyak 30 orang responden.

\section{Pengumpulan, Pengolahan dan Analisis Data}

Instrumen penelitian yang digunakan yaitu lembar observasi (Inriani et al., 2021), sphigmanometer (Onemed Tensi 200) dan stetoskop (GEA SF-411).

Senam yang dilakukan termasuk jenis senam jantung khusus untuk penderita hipertensi yang pelaksanaannya telah rutih satu kali dalam seminggu di Puskesmas Soropia dan dipandu oleh instruktur terlatih, sehingga peserta senam dari kelompok polanis tersebut sudah menguasai gerakan-gerakan senam. 
Pelaksanaan penelitian ini mengukuti jadwal senam prolanis dari Puskesmas Soropia yang dilakukan secara berturut-turut dalam waktu 3 pekan, dimana lama waktu senam dari awal (pemanasan) sampai dengan pada gerakan akhir (pendinginan) lebih kurang 30 menit.

Sebelum senam dilakukan tim peneliti mengukur tekanan darah kepada seluruh responden (prates) dan kemudian 10 atau 15 menit setelah senam Prolanis, dilakukan pengukuran TD kembali (pascates). Hasil pengukuran dicatat di dalam lembar observasi. Prosedur yang sama dilakukan mulai minggu I-III selama 3 minggu kegiatan senam dan semua responden hadir mengikuti kegiatan hingga selesai.

Analisis univariat digunakan untuk mengetahui distribusi frekuensi dan sebaran data yang telah dikumpulkan, sedangkan analisis bivariat menggunakan uji statistik Wilcoxon Signed Rank dengan tingkat kepercayaan 95\% (Arikunto, 2014). Metode uji Wilcoxon Signed Rank digunakan sebab data TD tidak berdistribusi normal $(\mathrm{P}<0.05)$.

\section{HASIL}

Tabel 1

Distribusi frekuensi karakteristik responden

\begin{tabular}{|c|c|c|}
\hline Karakteristik Responden & Jumlah $(\mathrm{N}=30)$ & Persentase (100\%) \\
\hline \multicolumn{3}{|l|}{ Kelompok umur (tahun) } \\
\hline $36-45$ & 10 & 33,3 \\
\hline $46-55$ & 16 & 53,4 \\
\hline$>55$ & 4 & 13,3 \\
\hline \multicolumn{3}{|l|}{ Jenis kelamin } \\
\hline Laki-laki & 17 & 56,7 \\
\hline Perempuan & 13 & 43,3 \\
\hline \multicolumn{3}{|l|}{ Pekerjaan } \\
\hline IRT & 8 & 26,7 \\
\hline Nelayan & 10 & 33,3 \\
\hline Petani & 2 & 6,6 \\
\hline PNS & 5 & 16,7 \\
\hline Wiraswasta & 5 & 16,7 \\
\hline
\end{tabular}

DOI: https://doi.org/10.36990/hijp.v13i1.232.g533

Pada tabel 1 diketahui bahwa rerata umur responden yang menderita hipertensi adalah 48,30 tahun. Lebih banyak penderita dengan jenis kelamin laki-laki yaitu 17 orang (56,7\%), dan sebagian besar pendrita hipertensi bekerja sebagai nelayan yaitu 10 orang $(33,3 \%)$. 
Tabel 2

Distribusi frekuensi variabel tekanan darah

\begin{tabular}{lllll}
\hline \multicolumn{1}{c}{ Tekanan Darah } & Min & Maks & Rata-rata/Std. Deviasi \\
\hline Prates & & & & \\
& Sistol & 148 & 178 & $\begin{array}{l}160,10 / 6,820 \\
\\
\end{array}$ \\
& Diastol & 86 & 110 & $94,50 / 6,350$ \\
\hline Pascates & & & & \\
& Sistol & 142 & 159 & $151,47 / 4,117$ \\
& Diastol & 82 & 94 & $87,07 / 3,005$ \\
\hline
\end{tabular}

DOI: https://doi.org/10.36990/hijp.v13i1.232.g534

Terjadi penurunan TD sistol maupun diastol setelah senam Prolanis, dimana TD sistol pretest yaitu $160,10 \mathrm{mmHg}$ menurun setelah posttest menjadi 151,47 mmHg, sedangkan untuk TD diastole pretest yaitu $94,50 \mathrm{mmHg}$ menurun setelah posttest menjadi $87,07 \mathrm{mmHg}$.

Tabel 3

Hasil uji statistik antar variabel

\begin{aligned} & \hline Tekanan Darah Nilai $\mathbf{P} \\ &$\hline Pra-pascates \\ & Sistol 0,001 \\ & Diastol 0,001 \\ & \hline\end{aligned}

DOI: https://doi.org/10.36990/hijp.v13i1.232.g535

Berdasarkan uji statistik Wilcoxon signed rank dengan tingkat kepercayaan 95\% untuk kedua variabel tekanan darah (sistol dan diastol) pra-pascates diperoleh nilai P $0,001(<0,05)$.

\section{PEMBAHASAN}

Diketahui bahwa rata-rata TD sistol hasil prates yaitu $160,10 \mathrm{mmHg}$ dengan yang terendah $148 \mathrm{mmHg}$ dan tertinggi adalah $178 \mathrm{mmHg}$, sedangkan rata-rata TD diastol yaitu $94,50 \mathrm{mmHg}$ dengan TD terendah adalah $86 \mathrm{mmHg}$ sedangkan TD tertinggi adalah $110 \mathrm{mmHg}$. Setelah senam Prolanis, hasil pengukuran kembali (pascates) dengan rata-rata TD sistol 151,47 $\mathrm{mmHg}$ dan rata-rata TD diastolnya adalah $87,04 \mathrm{mmHg}$ (Tabel 2). Proses pelaksanaan penelitian mulai minggu I, II dan III adalah sama, dimana mula-mula dilakukan pengukuran TD responden responden (prates) dan pascatesnya yaitu mengukur kembali tekanan darah 10-15 menit kemudian setelah responden mengakhiri senam Prolanis pada semua responden (Tabel 1 ).

Terjadi penurunan rata-rata tekanan darah sistol dan diastol antara sebelum dan setelah senam Prolanis. Penelitian lain yang sejalan juga menemukan hasil yang sama bahwa adanya penuruan tekanan darah (sistol-diastol), kendatipun selisih penurunannya tidak besar (Syamson et al., 2020). Dari studi yang dilakukan oleh Hasfika, Erawati, \& Sitorus (2020), sebelum diberikan senam 
Prolanis rerata tekanan darah sistol yaitu $151,18 \mathrm{mmHg}$ dan tekanan darah sistol setelah perlakukan senam Prolanis menurun menjadi 147,51 $\mathrm{mmHg}$, dan rerata TD diastol sebelum senam Prolanis adalah 97,39 $\mathrm{mmHg}$ dan menurun menjadi 89,04 mmHg setelah senam Prolanis (Hasfika et al., 2020). Hasil studi Dayanti (2019), peluang terjadinya penurunan tekanan darah sebesar 79,1\% bagi responden yang mengikuti latihan Prolanis secara teratur dan sebaliknya hanya sebesar 18,6\% pada responden yang tidak aktif mengikuti kegiatan senam Prolanis (Dayanti, 2019). Perilaku kesehatan seseorang seperti halnya tidak aktif secara fisik dalam arti tidak senam, hal ini berkaitan dengan terjadinya peningkatan risiko menderita hipertensi (Yodang \& Nuridah, 2019).

Perubahan TD sistol dan diastol yang dipengaruhi aktivitas seperti senam Prolanis bahwa tekanan darah arteri meningkat dan dinding arteri mengalami peregangan yang selanjutnya terjadi rangsangan baroreseptor pada sinus karotis termasuk arteri pada leher dan toraks yang memicu peningkatan impuls ke otak dan menyebabkan stimulus dari saraf otonom (simpatis) sehingga terjadi perubahan curah jantung dan resistensi perifer, diameter arteri meningkat dan pada kondisi inilah TD menurun (Baughman \& Hackley, 2013). Aktifitas fisik yang meningkat dapat menurunkan laju peningkatan TD sistol dari waktu ke waktu dan dapat menunda waktu terjadinya hipertensi, selanjutnya ketidakpatuhan sesorang terhadap terapeutik yang direkomendasikan petugas kesehatan merupakan pencetus utama buruknya kontrol hipertensi dan menjadi penghalang untuk mengurangi kematian akibat gangguan pembuluh darah di otak (Whelton \& Carey, 2018).

\section{Senam Prolanis dan Perubahan Tekanan Darah}

Hasil uji statistik menggambarkan bahwa terdapat pengaruh senam Prolanis terhadap perubahan TD pada penderita hipertensi (Tabel 3).

Aktivitas fisik yang dilakukan secara rutin dan berkesinambungan akan berdampak pada perubahan TD penderita hipertensi, sehingga meminimalkan risiko serangan jantung, stroke dan penyakit pembuluh darah lainnya (Comang et al., 2018). Aktivitas fisik rutin (olahraga teratur) dapat menurunkan tekanan darah hingga 5-7 mmHg dalam waktu 22 jam setelah kegiatan berolahraga (Comang et al., 2018; Hanik, 2018; Sidiq, 2019; Thei et al., 2018).

Aktivitas fisik memiliki manfaat penting bagi penderita penyakit tidak menular, setelah kegiatan latihan yang dilakukan secara rutin akan dapat meningkatkan imunitas tubuh, meregulasi kadar gula darah, mencegah obesitas/ berat badan meningkat, memaksimalkan sensitivitas reseptor insulin, dan dapat menurunkan TD bagi penderita hipertensi serta dapat meningkatkan kebugaran untuk bekerja/beraktivitas (Kementerian Kesehatan RI, 2020; Ramadhan, 2017; Tiksnadi et al., 2020). Lebih lanjut dengan adanya senam Prolanis, senam kategori jantung ini memiliki manfaat seperti halnya pada perbaikan profil lemak darah, mencegah peningkatan kolesterol total, Low Density Lipoprotein (LDL), trigliserida, serta meningkatkan High Density Lipoprotein (HDL) dan dapat mempertahankan stabillitas TD termasuk sistem keseimbangan lain di dalam tubuh pada umumnya (Rahmawati \& Aizza, 2018).

Senam Prolanis dapat menstimulasi aktivitas kerja sistem kardiovaskuler, artinya dengan olahraga maka kebutuhan energi oleh sel-sel jaringan serta organ 
tubuh dapat ditingkatkan (Fahlevi et al., 2019). Peningkatan energi tersebut akan berdampak pada kerja pernafasan otot rangka dan menyebabkan stimulasi saraf simpatis sehingga aktivitas jantung dan frekuensi jantung meningkat (Buana, 2012). Aktivitas pompa jantung untuk memenuhi kebutuhan sel-sel tubuh menyebabkan jantung berdenyut lebih cepat dalam jumlah tertentu, dan kecepatan jantung dan volume sekuncup menurun, serta vasodilatasi arteriol vena. Oleh karena penurunan ini menyebabkan curah jantung dan resistensi perifer total menurunan sehingga terjadi penurunan tekanan darah (Comang et al., 2018; Marasinta, 2016).

Senam ergonomik yang salah satunya adalah senam prolanis berdampak terhadap tekanan darah lansia yang mengalami hipertensi (Alifatun, 2019; Hasanah, 2018). Studi lain oleh Zuraidah et al. (2012) dan Hasfika et al. (2020) tentang analisis hubungan kebiasaan responden dengan kejadian hipertensi bahwa kebiasaan melakukan olahraga selama kurang lebih 30 menit memiliki hubungan yang signifikan terhadap penurunan TD pada penderita hipertensi (Hasfika et al., 2020; Zuraidah et al., 2012).

\section{KESIMPULAN DAN SARAN}

Terjadi penurunan tekanan darah sistol dan diastol pada lansia penderita hipertensi yang mengikuti senam prolanis selama tiga minggu di Puskesmas Soropia Kabupaten Konawe yang secara statistik terdapat hubungan antara senam Prolanis dengan penurunan tekanan darah ini.

\section{Kekurangan Penelitian}

Tidak adanya kontrol terhadap kebiasaan perilaku responden selama penelitian yang juga bisa memicu terjadinya peningkatkan atau penurunan tekanan darah seperti konsumsi obat anti hipertensi, konsumsi makanan yang tinggi natrium sebab responden tinggal di wilayah pesisir dengan penghasilan makanan laut yang tinggi kolesterol, dan dapat pula terjadi stres yang mengganggu kesehatannya. Pada peneliti lainnya agar dapat mengontrol faktor-faktor mempengaruhi penurunan tekanan darah dan perlu adanya jumlah sampel yang lebih besar dengan desain kelompok pembanding atau kontrol.

\section{DAFTAR PUSTAKA}

Alifatun, V. D. (2019). Pengaruh senam ergonomik terbadap tekanan darah lansia mengalami hipertensi di dusun kanugrahan desa kanugrahan kecamatan maduran kabupaten lamongan [Undergraduate Thesis]. https://rama.ristekbrin.go.id/doc ument/detail/oai:repository.unair.ac.id:91250-154

Arikunto S. (2010). Prosedur penelitian : suatu pendekatan praktik. Rineka Cipta. https://isbn.perpusnas.go.id/Account/SearchBuku?searchTxt=978-979098-095-2\&searchCat=ISBN

Badan Penyelenggaraan Jamin Sosial Kesehatan Masyarakat (BPJS). (2015). Panduan Praktis Prolanis (Program pengelolaan penyakit kronis). https://www.bpjs-keseha tan.go.id/bpjs/dmdocuments/06-PROLANIS.pdf 
Baughman, D \& Hackley, J. (2013). Buku saku keperawatan medikal-bedah Brunner \& Suddarth.EGC. https://isbn.perpusnas.go.id/Account/SearchBuku?searchTxt= 979-044-470-68searchCat=ISBN

Buana, G. C. Herawati, I. Widodo, A. (2012). Hubungan antara kebugaran kardiorespirasi dengan Tekanan Darah pada Wanita Usia 30-39 Tahun [Undergraduate Thesis].

Carey, R. M., Muntner, P., Bosworth, H. B., \& Whelton, P. K. (2018). Prevention and Control of Hypertension: JACC Health Promotion Series. Journal of the American College of Cardiology, 72(11), 1278-1293. https://doi.org/10.1016/j.j acc.2018.07.008

Comang, C., Susanti, R. W., Asrul, M., \& Hidayatullah, M. (2018). Pengaruh Low Impact Aerobic Terhadap Penurunan Tekanan Darah Pada Pasien Hipertensi Di Wilayah Kerja Puskesmas Tetewatu Kabupaten Konawe Utara Tahun 2018. Jurnal Keperawatan\#: Jurnal Penelitian Disiplin Ilmu Keperawatan, 2(2). https:/ /garuda.kemdikbud.go.id/documents/detail/2125240

Dayanti, I (2019). Hubungan senam prolanis terhadap penurunan tekanan darah pada pasien hipertensi di UPTD Puskesmas Lompoe Kota Parepare. Jurnal Ilmiah Kesehatan Iqra, 7(2). https://garuda.ristekbrin.go.id/documents/detail/168820 5

Dinas Kesehatan Konawe. (2018). Profil Dinas Kasehatan Kabupaten Konawe [Unpublished report]. Dinas Kesehatan Kabupaten Konawe.

Dinkes Sultra. (2018). Profil Kesehatan Provinsi Sulawesi Tenggara Tahun 2017. Dinas Kesehatan Provinsi Sulawesi Tenggara. https://www.kemkes.go.id/resources/do wnload/profil/PROFIL_KES_PROVINSI_2017/28_Sultra_2017.pdf

Fahlevi, A. R., Riyadi, A., \& Mardiani. (2019). Senam Prolanis Menurunkan Tekanan Darah Lansia Penderita Hipertensi.Journal Keparawatan Raflesia, 1(November), 119-128. https://doi.org/10.33088/jkr.v1i2.401

Hanik, U. (2018). Pengaruh Senam Ergonomik Terhadap Penurunan Tekanan Darah Pada Lansia Yang Mengalami Hipertensi (Studi di Posyandu Lansia Desa Jabon Kecamatan Jombang Kabupaten Jombang) [Undergraduate Thesis]. https://rama .kemdikbud.go.id/document/detail/oai:repo.stikesicme-jbg.ac.id:516-35

Hasanah, U. (2018). Pengaruh Senam Ergonomis Terhadap Penurunan Tekanan Darah Pada Lansia Penderita Hipertensi Di Dusun Pundung Nogotirto Gamping Sleman Yogyakarta. Naskah Publikasi Fakultas Ilmu Kesehatan Universitas 'Aisyiyah. https://rama.ristekbrin.go.id/document/detail/oai:digilib.unisayogya. ac.id:4554-126

Hasfika, I., Erawati, S., \& Sitorus, F. E. (2020). Pengaruh Senam Prolanis Terhadap Pengendalian Kadar Glukosa Darah dan Tekanan Darah Pada Pasien Diabetes Melitus Tipe II dan Hipertensi. Best Journal (Biology Education Science \&Technology), 3(2),184-190. https://doi.org/10.30743/best.v3i2.3226

Inriani, Narmawan, \& Abadi, Ellyani. (2021). Set Data Kajian Senam Prolanis dan Tekanan Darah di Puskesmas Soropia [Data set]. Zenodo. http://doi.org/10.528 1/zenodo.4905192

Kementerian Kesehatan RI. (2018). Hasil Utama Riskesdas 2018. https://kesmas.kemkes.go.id/assets/upload/dir_519d41d8cd98f00/files/ Hasil-riskesdas-2018_1274.pdf

Kementerian Kesehatan RI. (2020). Aktivitas Fisik di Masa Pandemi COVID-19 Bagi Orang dengan Faktor Risiko PTM (3). http://www.p2ptm.kemkes.go.id/kegiatan-p2ptm/dki-jakarta/aktivitas-fisi k-di-masa-pandemi-covid-19-bagi-orang-dengan-faktor-risiko-ptm-3 
Marasinta, I. S. (2016). Pengarub Senam Aerobik Low Impact Terbadap Penurunan Tekanan Darah Tinggi Pada Lanjut Usia [Unvergraduate Thesis].

Mulfianda, R., Tahlil, T., \& Mulyadi, M. (2018). Pengaruh Senam Prolanis Terhadap Tekanan Darah Dan Gula Darah Sewaktu Pada Lansia.Jurnal Ilmu Keperawatan, 6(2). https://garuda.kemdikbud.go.id/documents/detail/1619875

Puskesmas Soropia. (2019). Profil Puskesmas Soropia [Unpublished Document]. Puskesmas Soropia.

Puskesmas Soropia. (2020). Buku Register Kunjungan Rawat Jalan Puskesmas Soropia [Unpublished Document]. Puskesmas Soropia.

Rahmawati, L., \& Aizza, N. (2018). Pengaruh Senam Prolanis Terhadap Penurunan Tekanan Darah Pada Lansia Di Desa Glagahwero Kecamatan Panti Kabupaten Jember. The Indonesian Journal of Health Science, September, 150. https://doi.or g/10.32528/ijhs.v0i0.1539

Ramadhan, M. (2017). Faktor yang Berhubungan dengan Kejadian Diabetes Mellitus di RSUP DR Wabidin Sudirohusodo dan RS Universitas Hasanuddin makassar Tabun 2017 [Undergraduate Thesis]

Sari, P. D. P. (2017). Hubungan programpengelolaan penyakit kronis (prolanis) terhadap status kesehatan penderita hipertensi [Undergraduate Thesis]. https://rama.kemd ikbud.go.id/document/detail/oai:repo.stikesicme-jbg.ac.id:106-35

Sartik., Tjekyan, R. S., \& Zulkarnain, M. (2017). Faktor-Faktor Risiko Dan Angka Kejadian Hipertensi Pada Penduduk Palembang. Jurnal Kesehatan Masyarakat, 8(3), 180-191.

Sidiq, M. N. (2019). Pengaruh Senam Prolanis Terhadap Tekanan darah pasien hipertensi di Puskesmas Purwodingratan Kota Surakarta [Undergraduate Thesis]. https://rama.kemdikbud.go.id/document/detail/oai:eprints.ums.ac.id:7 2950-240

Syamson, M. M., Fitri, N., \& Hasrul, H. (2020). Pengaruh senam prolanis terhadap penurunan tekanan darah pada penderita hipertensi. Holistik Jurnal Kesehatan, 14(1), 74-81. https://doi.org/10.33024/hjk.v14i1.2330

Thei, A. D.., Sambriong, M., \& Gatum, A. (2018). Pengaruh senam ergonomik terhadap penurunan tekanan darah pada lansia yang mengalami hipertensi di UPT Panti sosial penyantun budi agung kota Kupang. Jurnal Stikes CMHK, 4(3), 18-22.

Tiksnadi, B. B., Sylviana, N., Cahyadi, A. I., \& Undarsa, A. C. (2020). Olahraga Rutin untuk Meningkatkan Imunitas Pasien Hipertensi Selama Masa Pendemi COVID-19. Indonesian Journal of Cardiologi, 41(2). https://doi.org/10.30701/ ijc. 1016

Whelton, P. K., \& Carey, R. M. (2018). 2017 ACC / AHA / AAPA / ABC / ACPM / AGS / APhA / ASH / ASPC / NMA / PCNA Guideline for the Prevention, Detection, Evaluation, and Management of High Blood Pressure in Adults. Journal of the American Collage of Cardiology, 71(19). https://doi.org/1 0.1016/j.jacc.2017.11.006

WHO. (2019). Hypertension. https://www.who.int/news-room/fact-sheets/detail/hy pertension.

Yodang, Y., \& Nuridah, N. (2019). Prevalence and Determinants of Hypertension in Coastal and Estuarine Communities. International Journal Medical Reviews, 6(4), 128-134. https://doi.org/10.30491/IJMR.2019.100909

Zuraidah, Z. Maksuk, M., \& Apriliadi, N (2012). Analisis faktor risiko penyakit hipertensi pada masyarakat di kecamatan kemuning kota palembang tahun 2012. 
JPP (Jurnal Kesehatan Poltekkes Palembang), 1(10). https://garuda.kemdikbud. go.id/documents/detail/1047065

\section{Catatan kaki}

Catatan Penerbit Poltekkes Kemenkes Kendari menyatakan tetap netral sehubungan dengan klaim atas perspektif atau buah pikiran yang diterbitkan dan dari afiliasi institusional manapun.

Pernyataan Konflik Kepentingan Para penulis menyatakan tidak terdapat konflik kepentingan.

Kontribusi Penulis Para penulis tidak mendeklarasikan kontribusinya.

Berbagi Data Data hasil kajian disimpan pada komunitas health information : jurnal penelitian data sharing dan dapat dikunjungi melalui http://doi.org/10.5281/zenodo.4905192 .

\section{Author notes}

narmawanfebson@gmail.com 